\title{
Profile of Urinary Tract Infections in the Elderly in the Internal Medicine Department of the University Hospital Center of Point G, Bamako, Mali
}

\author{
Drissa Sangaré1,2, Magara Samakée, ${ }^{2 *}$, Nanko Doumbia ${ }^{2,4}$, Aboubacar Sidiki Fofana ${ }^{3}$, \\ Sékou Mamadou Cissé1, Seydou Sy ${ }^{2,5}$, Atabième Kodio ${ }^{5}$, Moctar Coulibaly6, \\ Sah dit Baba Coulibaly7, Djibril Sy2,8, Kaya Assétou Soucko',8, Mamadou Dembélée,8, \\ Saharé Fongoro 2,5
}

\footnotetext{
${ }^{1}$ Department of Medicine and Medical Specialty, The Fousseyni Daou Hospital, Kayes, Mali

${ }^{2}$ Faculty of Medicine of Bamako, Bamako, Mali

${ }^{3}$ Nephrology Unit of Fousseyni Daou Hospital, Kayes, Mali

${ }^{4}$ Medicine Department of Mali Hospital, Bamako, Mali

${ }^{5}$ Nephrology Department of the University Hospital Center of Point G, Bamako, Mali

${ }^{6}$ Nephrology Unit of Mali Gavardo Hospital, Bamako, Mali

${ }^{7}$ Nephrology Unit of Somino Dolo Hospital, Mopti, Mali

${ }^{8}$ Internal Medicine Department of the University Hospital Center of Point G, Bamako, Mali

Email: ^samake_magara@yahoo.fr
}

How to cite this paper: Sangaré, D., Samaké, M., Doumbia, N., Fofana, A.S., Cissé, S.M., Sy, S., Kodio, A., Coulibaly, M., dit Baba Coulibaly, S., Sy, D., Soucko, K.A., Dembélé, M. and Fongoro, S. (2021) Profile of Urinary Tract Infections in the Elderly in the Internal Medicine Department of the University Hospital Center of Point G, Bamako, Mali. Open Journal of Nephrology, 11, 217-229.

https://doi.org/10.4236/ojneph.2021.112017

Received: April 15, 2021

Accepted: May 23, 2021

Published: May 26, 2021

\begin{abstract}
Introduction: Urinary tract infections (UTI) are frequent and of polymorphous clinical symptomatology in elderly subjects both in and out of hospital. In Mali, to our knowledge, no study concerning UTIs in the elderly has been conducted, hence the interest in this innovative work. Objectives: To determine the prevalence and clinical and paraclinical aspects of urinary tract infections in the elderly. Materials and Methods: This was a prospective descriptive and cross-sectional study from September 1, 2013 to August 31, 2014, i.e. duration of 12 months. All patients aged 65 years and over, hospitalized or ambulatory in the internal medicine department with a documented urinary tract infection were included. Results: We collected and examined 194 patients. The cytobacteriological study of urine (CBSU) was positive in 28 patients, i.e. a prevalence of $14.43 \%$. The male sex represented $59.8 \%$ of the cases, the sex ratio was equal to 1.46. The age groups between 65 - 69 and 70 74 years were the most affected, respectively $28.57 \%$ and $39.28 \%$. The main clinical signs were: asthenia, anorexia, dependence, fever, urinary burning, dysuria. Hospitalization was associated with urinary tract infection with $\mathrm{P}=$
\end{abstract}


Copyright $\odot 2021$ by author(s) and Scientific Research Publishing Inc. This work is licensed under the Creative Commons Attribution International License (CC BY 4.0).

http://creativecommons.org/licenses/by/4.0/
0.01 . The group of enterobacteria were incriminated in $75 \%$ of cases. Escherichia coli, Klebsiella pneumoniae and Pseudomonas aeruginosa represented $39.28 \%, 14.28 \%$ and $10.71 \%$ of cases. Urinary tract infections were represented by pyelonephritis, acute prostatitis, orchi-epididymitis and simple cystitis. Conclusion: Urinary tract infection is frequent in the elderly, its clinical presentation is polymorphic and enterobacteria are the most incriminated group of bacteria.

\section{Keywords}

Urinary Tract Infection, Elderly Subject, Internal Medicine, Point G Hospital, Mali

\section{Introduction}

Urinary tract infections (UTI) are frequent and of polymorphous clinical symptomatology in elderly subjects both in and out of hospital [1] [2] [3]. In the community, they rank second after bronchial and pulmonary infections [4] [5]. In the hospital setting, they rank first [3]. They are a public health problem both in terms of management and cost and are a daily problem [6]. They are the most frequently treated bacterial infections in the elderly in institutions [7]. In the city, the prevalence of urinary tract infections is estimated at 140/1000 in women over 75 years of age and at 50/1000 in men [8]. This difference in prevalence is historically explained by the greater distance between the urethral meatus and the anus in men, a drier environment at the urethral opening, a longer urethra and antibacterial activity of prostatic secretions [9].

In Tunisia, the prevalence of UTI in the Internal Medicine Department of Habib Thameur Hospital between January 2002 and December 2006 was 16.6\%. It seems to be higher in elderly subjects than in those under 65 years of age with $35.2 \%$ and $17.9 \%$ respectively [2].

In Morocco, the prevalence rate of urinary tract infections at the Military Hospital Instruction Mohamed V in Rabat is $17.49 \%$, i.e. $7.18 \%$ among outpatients and $10.31 \%$ among inpatients over 65 years of age [10].

In Mali, to our knowledge no study concerning UTI in the elderly specifically has been conducted hence the interest of this study.

The objectives of this study were to determine the prevalence and the clinical and paraclinical aspects of urinary tract infections in the elderly.

\section{Materials and Methods}

This was a prospective, descriptive, cross-sectional study from September 1, 2013 to August 31, 2014, i.e. duration of 12 months. Were included, all patients aged 65 years and over, hospitalized or outpatient in the department of Internal Medicine presenting a documented urinary tract infection.

For each patient, the interrogation allowed to note on an individual survey 
form the following data:

- Functional complaints: alteration of the general state, fever, agitation, delirium and incoherent speech, constipation, diarrhea, vomiting, pollakiuria, polyuria, urinary incontinence, suprapubic and or lumbar pain.

- Physical signs: large kidneys (lumbar contact), suprapubic and lumbar pain, bladder globe, prostate hypertrophy-Complementary tests: CBC, ESR, CRP, blood glucose, creatinine, CBSU (cytological and bacteriological study of urine), uroculture, antibiotic susceptibility test, blood culture, abdomino-pelvic ultrasound, abdomino-pelvic scanner.

- History: Hypertension, Diabetes, HIV, surgery on the urinary tract: kidneys, ureters, prostate, bladder.

\section{Operational definitions:}

- Urinary tract infection: positive urine cytobacteriological examination associated with at least one of the following signs;

- Temperature $\geq 38.5^{\circ} \mathrm{C}$ or hypothermia $\leq 36.5^{\circ} \mathrm{C}$;

- Dysuria;

- Pollakiuria;

- Burning of the bladder;

- Suprapubic tension;

- Recent urinary incontinence;

- Drowsiness, onset or worsening of anorexia, disorientation, dependence.

The CBSU is said to be positive if:

* with no catheterization: leukocyturia $>105 \mathrm{CFU} / \mathrm{ml}$ with 1 or 2 species of bacteria on culture, ${ }^{*}$ with round-trip catheterization: leukocyturia $>102 \mathrm{CFU}$ $/ \mathrm{ml}$ with 1 or more species of bacteria on culture [11].

- Urinary colonization or asymptomatic bacteriuria: this is the presence of a microorganism in the urine without associated clinical manifestations. There is no bacteriuria threshold, except in pregnant women, where a bacteriuria threshold of $105 \mathrm{CFU} / \mathrm{ml}$ is classically used.

Elderly patient: any person over 65 years of age, whether retired, able-bodied or disabled with at least 3 criteria of frailty or over 75 years of age [12] [13].

- Nosocomial urinary tract infections or hospital-acquired infections: urinary tract infections acquired during a hospital stay and which were neither present nor incubating at the time of the patient's admission. They occur more than 48 hours after admission and are usually considered nosocomial [14] [15].

Community-acquired urinary tract infections: urinary tract infections acquired in the city at a distance from any hospital or therapeutic stay. They manifest themselves in less than 48 hours after hospitalization.

- Recurrent cystitis: they are defined by the occurrence of at least 4 episodes during 12 consecutive months [13].

- Pyelonephritis: microbial inflammation of the pelvis associated with invasion of the interstitium by suppurative streaks. It can be primary (without urological lesions) or secondary (following a uropathy or an obstacle), acute or 
chronic.

- Simple urinary tract infections: urinary tract infection (UTI) occurring in patients with no risk factors for complications [13].

- Severe urinary tract infections.

These are acute pyelonephritis and male UTI associated with:

- Severe sepsis;

- Septic shock;

- An indication for surgical or interventional drainage (risk of aggravation of sepsis in the perioperative period) [13].

Urinary tract infections at risk of complication: these are UTI occurring in patients with at least one risk factor that can make the infection more serious and the treatment more complex [13]. The risk factors for complication are:

- Any organic or functional abnormality of the urinary tree (bladder residue, reflux, lithiasis, tumor, recent procedure ...).

- Male gender, because of the frequency of underlying anatomical or functional anomalies.

- Pregnancy.

- Elderly subject: patient over 65 years old with $>3$ criteria of frailty (Fried criteria), or patient over 75 years old.

- Severe immunodepression.

- Severe chronic renal failure (clearance $<30 \mathrm{ml} / \mathrm{min}$ ) [13].

- Fried criteria:

- Involuntary weight loss in the past year.

- Slow walking speed.

- Low stamina.

- Weakness/tiredness.

- Reduced physical activity [13].

Data entry and analysis were performed using Microsoft WORD 2007 and SPSS Software version 20.0. For the comparison of our proportions we used the Chi-square test with $\mathrm{p}<0.05$.

Informed consent was obtained from the patients included in our study. In case of major disability, the consent of the family was requested. The anonymity and confidentiality of the results were assured.

\section{Results}

We collected and examined 194 patients according to our inclusion criteria during the study period. The CBSU was positive in 28 patients, a prevalence of $14.43 \%$. The male sex represented $59.8 \%$ of the cases, with a sex ratio of 1.46 . The average age was $69 \pm 2$ years. The age groups between $65-69$ and $70-74$ years were the most affected, respectively $28.57 \%$ and $39.28 \%$.

The main clinical signs were: physical asthenia, anorexia, dependence, fever, urinary burning, dysuria. They were more marked in hospital than in the outpatient setting (Cf. Table 1). 
Hospitalization was associated with urinary tract infection with $\mathrm{p}=0.01$ (Cf. Table 2). It occurred in patients with the following comorbidities: HTA (10 cases), Liver cancer (5 cases) cirrhosis (7 cases), diabetes (7 cases) and heart failure (6 cases). Urinary tract infections were represented by pyelonephritis, acute prostatitis, orchi-epididymitis and simple cystitis. Trans-urethral urinary catheterization was associated with urinary tract infection with $\mathrm{p}<0.005$ (Cf. Table 3). Enterobacteriaceae was incriminated in $75 \%$ of cases. Escherichia coli, Klebsiella pneumoniae and Pseudomonas aeruginosa accounted for $39.28 \%, 14.28 \%$ and $10.71 \%$ of the cases (see Table 4 ). Of the 28 cases of confirmed UTIs, 22 were hospitalized with 14 males and 8 females, and Escherichia coli represented $41 \%$ of the germs found. In outpatient settings, urinary tract infection was more frequent in women (4 cases) with $33.3 \%$ of $E$. Coli. Trans-urethral urinary catheterization and Escherichia coli were respectively the most common factors for urinary tract infection (18 cases/28) and the most common germ isolated by cytobacteriological examination of urine (11 cases). Prostatic obstruction and diabetes were the other factors responsible for the frequent presence of Escherichia Coli in our study. All the germs found at the CBSU had in common the presence of a trans-urethral urinary catheter (Cf. Table 5).

Table 1. Distribution of 28 patients with urinary tract infection according to symptomatology and origin.

\begin{tabular}{|c|c|c|c|}
\hline Symptoms & Outpatient & Hospitalization & Total \\
\hline Pollakiuria & 1 & 10 & 11 \\
\hline Burning of the bladder & 3 & 12 & 15 \\
\hline Dysuria & 2 & 10 & 12 \\
\hline Pelvic pain & 0 & 9 & 9 \\
\hline Vomiting & 2 & 12 & 14 \\
\hline Gross hematuria & 0 & 1 & 1 \\
\hline Low back pain & 1 & 5 & 6 \\
\hline Urinary incontinence & 0 & 11 & 11 \\
\hline Fiver & 3 & 13 & 16 \\
\hline Hypothermia & 0 & 2 & 2 \\
\hline Thrill & 2 & 8 & 10 \\
\hline Confusion & 0 & 8 & 8 \\
\hline Fall & 0 & 2 & 2 \\
\hline Anorexia & 2 & 16 & 22 \\
\hline Asthenia & 5 & 18 & 23 \\
\hline Karnofsky dependency $<45 \%$. & 1 & 17 & 18 \\
\hline
\end{tabular}


Table 2. Distribution of patients according to their origin and urinary infections.

\begin{tabular}{cccc}
\hline & Outpatient & Hospitalization & Total \\
\hline Presence of UTI & $6(3.09 \%)$ & $22(11.34 \%)$ & $28(14.43 \%)$ \\
Absence of UTI & $78(40.21 \%)$ & $88(45.36 \%)$ & $166(85.57 \%)$ \\
Total & $84(43.30 \%)$ & $110(56.70 \%)$ & $194(100 \%)$ \\
\hline
\end{tabular}

$\mathrm{p}=0.01$

Table 3. Distribution of patients according to the trans-urethral urinary catheter and urinary infection.

\begin{tabular}{cccc}
\hline Urinary catheterization & Presence of UTI & Absence of UTI & Total \\
\hline Presence of a survey & $18(9.28 \%)$ & $10(5.15 \%)$ & $28(14.43 \%)$ \\
Absence of survey & $10(5.15 \%)$ & $156(84.42 \%)$ & $166(85.57 \%)$ \\
Total & $28(14.43 \%)$ & $166(85.57 \%)$ & $194(100 \%)$ \\
\hline
\end{tabular}

$\mathrm{p}<0.005$.

Table 4. Distribution of bacteria responsible for infections according to their morphology and group.

\begin{tabular}{|c|c|c|c|c|c|c|}
\hline Morphology & Groupe & Group frequency & Groupe \% & Species & Group frequency & Species \% \\
\hline \multirow{7}{*}{$\begin{array}{c}\text { Gram } \\
\text { negative } \\
\text { bacilli }\end{array}$} & \multirow{7}{*}{ Enterobacteria } & \multirow{7}{*}{21} & \multirow{7}{*}{$75 \%$} & Escherichia coli & 11 & $39.28 \%$ \\
\hline & & & & Klebsiella pneumoniae & 4 & $14.28 \%$ \\
\hline & & & & Pseudomonas aeruginosa & 3 & $10.71 \%$ \\
\hline & & & & Acinetobacter $s p$ & 1 & $3.57 \%$ \\
\hline & & & & Enterobacter cloacae & 1 & $3.57 \%$ \\
\hline & & & & Proteus mirabilis & 1 & $3.57 \%$ \\
\hline & & & & Streptococcus $s p$ & 3 & $10.71 \%$ \\
\hline \multirow{3}{*}{$\begin{array}{c}\text { Gram } \\
\text { positive } \\
\text { cocci }\end{array}$} & Streptococci & 5 & \multirow{3}{*}{$25 \%$} & Streptococcus non groupable & 2 & $7.14 \%$ \\
\hline & Staphylococci & 1 & & Staphylococcus à coagulas négatif & 1 & $3.57 \%$ \\
\hline & Enterococci & 1 & & Enterococcus & 1 & $3.57 \%$ \\
\hline Total & & 28 & $100 \%$ & & 28 & $100 \%$ \\
\hline
\end{tabular}

Table 5. Distribution of the 28 patients according to the factors favouring urinary tract infection and the germs isolated.

\begin{tabular}{|c|c|c|c|c|}
\hline Bacteria & Diabetes & Urinary catheter & Prostate adenoma & Total \\
\hline Escherichia coli & 3 & 5 & 3 & 11 \\
\hline Klebsiella pneumoniae & 1 & 3 & 0 & 4 \\
\hline Pseudomonas aeruginosa & 1 & 2 & 0 & 3 \\
\hline Streptococcus $s p$ & 1 & 2 & 0 & 3 \\
\hline Streptococcus non groupable & 0 & 2 & 0 & 2 \\
\hline Acinotobacter $s p$ & 0 & 2 & 0 & 1 \\
\hline Proteus mirabilis & 0 & 1 & 0 & 1 \\
\hline Staphylococcus à coagulase negatif & 0 & 1 & 0 & 1 \\
\hline Enteroccus foecalis & 0 & 1 & 0 & 1 \\
\hline Enterobacter cloacae & 1 & 1 & 0 & 1 \\
\hline Total & 7 & 18 & 3 & 28 \\
\hline
\end{tabular}




\section{Discussion}

Of the 276 patients seen during the study period, 194 met the inclusion criteria, of whom $28 \mathrm{CBSU}$ were positive, i.e. a prevalence of $14.43 \%$. This high prevalence of hospital-acquired UTIs in our series could be explained by the frequent recruitment of patients who had stayed in the emergency department and had been subject to repeated urinary catheterization. Besma Ben Dhaou Hmaidi in Tunisia, Maxwell in Morocco and Traoré in the nephrology department of the university hospital center of Point G reported respective prevalences of $16.6 \%$, $17.49 \%$ and $15.6 \%$ [2] [10] [16]. The male sex represented $59.8 \%$ of the cases, with a sex ratio of 1.46. Our results are in agreement with those of Maxell in Rabat who found a male predominance of $56.4 \%$, with a sex ratio of 1.29 [10].

On the other hand, the male predominance was not found by some authors; in Tunisia, Besma Ben Dhaou Hmaidi et al. [2] reported a sex ratio F/H of 0.35; at the University Hospital of Montpellier [17], in the department of internal medicine and acute geriatric care, the proportion of male cases was 1.46 is 2 to 3 women for every man; and it was 2 women for every man in subjects over 65 years old in Paris [18]. The age groups between 65 - 69 and 70 - 74 years were the most affected, with $28.57 \%$ and $39.28 \%$ respectively. Maxwel found in his study a total of $56.4 \%$ with an equal frequency of $28.2 \%$ for the two age groups 65 - 70 years and 70 - 75 years [10]. The clinical symptoms were dominated by dependence $(85 \%)$, asthenia $(82.14 \%)$, anorexia $(81.48 \%)$, fever $(57.14 \%)$, urinary burning $(53.57 \%)$, vomiting $(50 \%)$, chills $(35.71 \%)$, pollakiuria $(39.28 \%)$, urinary incontinence (39.28\%), lumbar and pelvic pain $(32.14 \%)$. These signs highlight the polymorphism of symptoms encountered in the elderly during urinary tract infections, and the misleading aspect of certain symptoms. Several studies report the atypical nature of UTI symptoms in the elderly [1] [2] [3] [19] [20] [21] [22].

Hospitalization was associated with UTI with $\mathrm{p}=0.01$, but not with length of hospitalization $(\mathrm{p}=0.49)$. This finding corroborates that reported in the literature [10] [20] [23].

The analysis of the history shows that UTI was more frequent in patients with the following pathologies: Hypertension (10 cases), Liver cancer (5 cases) cirrhosis ( 7 cases), diabetes ( 7 cases) and IC (6 cases). Concerning the antecedents or risk factors, we find ourselves in a polymorphic context with age and no factor is incriminated with certainty.

With advanced age, the elderly person accumulates functional fragility and numerous pathologies other than urological (diabetes, non-acquired immunodepression) which may favor urinary infection [14]. UTI are more frequent in inpatients $20 \%(22 / 110)$ than in outpatients $7.14 \%(6 / 84) \mathrm{p}=0.01$. Maxwel found UTI rates in inpatients and outpatients to be $10.31 \%$ and $7.18 \%$ respectively [10].

In 2009, De Wazières reported that nosocomial urinary tract infection increases with advancing age as does bacteriuria, unlike community-acquired UTI 
which are a frequent reason for consultation and medical prescription in routine practice [24]. In general, urinary tract infections seem to be more frequent in the elderly and in hospitals [2] [10]. Urinary tract infection was more frequent in patients with urinary catheters: $64.29 \%(18 / 28)$ than in those without catheters $(6.02 \%)$, with a statistically significant difference $(p=0.005)$. Maxwel in Rabat found few urinary tract infections in subjects with urinary catheters. This is probably due to good compliance of the medical services with the recommendations for urinary catheterization [10]. Our study shows a frequency of urinary tract infections in hospitalized patients, but it is not related to the length of hospitalization $(\mathrm{p}=0.49)$. This finding has been made by other authors [10] [20] [23].

As for the germs isolated, Gram-negative bacilli (GNB) were the most frequently identified in the culture media during our study, with Escherichia coli, Klebsiella pneumoniae and Pseudomonas aeroginosa in the lead. This has also been found in several international series [24] [25] [26]. From the review of the literature, it appears that BGN are frequently encountered in bacteriuria [2] [24]-[30].

Among the enterobacteria (gram bacille negatif) in our study, Escherichia coli was the most incriminated and isolated in $39.28 \%$ cases. In Tunisia in 2011, this bacterium was isolated in $58 \%$ of cases [2].

At the Mohamed V Military Hospital in Rabat in 2014, it was isolated in 59\% of cases [10]. For our study E. coli was followed by Klebsiella pneumoniae $14.28 \%$ and Pseudomonas aeroginosa $10.71 \%$, Streptococcus sp $10.71 \%$, for the rest, we isolated 3.57\% of Acinobacter Sp, Proteus mirabilisof coagulase-negative Staphylococcus, Entrococcus faecalis and Enterobacter cloacae.

In the literature, E. coli is the most incriminated in UTI [24]. According to the SPLIF 2014, E. coli is the most frequently encountered bacterium $(70 \%-95 \%)$ in community-acquired UTIs. It is followed by the other enterobacteria especially Proteus sp. and Klebsiella sp [13].

Faucher $\mathrm{N}$ and Cudenne T. in Paris found that E. coli is more frequent in elderly women in the community and in hospitals. On the other hand, in elderly men, E. coli is more frequent in the community; in the hospital, Proteus mirabilis is the most frequent [20] [31].

The frequency of Pseudomonas aeruginosa: $4.8 \%$ is similar to that found in a retrospective study of UTI at the Mohamed V Military Hospital in Rabat in 2013 [10].

For Gram-positive cocci in our study, we found the following proportions: $10.71 \%$ for Streptococcus $s p$ and $3.57 \%$ for non-groupable Streptococcus and coagulase-negative Staphylococcus. Maxwel reported for Gram-positive cocci a frequency of: 4.8\%, for Enterococcus faecalis and for group B Streptococcus, and $1.2 \%$ for coagulase-negative Staphylococcus was low [10]. The antibiotic susceptibility of the isolated germs was variable, thus Escherichia coli was resistant to amoxicillin (81.81\%); to amoxicillin + clavulanic acid (45.45\%). It was sensitive to ceftazidine $(72.72 \%)$, cefoxitine $(81.81 \%)$, imipenem $(81.81 \%)$, amikacin 
(90.90\%), gentamicin (72.72\%), ciprofloxacin (54.54\%), nalidixic acid (45.45\%), chloramphenicol (81.81\%), sulphamethoxazole + trimethoprim (27.27\%) and colistin (100\%). Traoré et al. reported in a study in 2012 a sensitivity of E coli to $89 \%$; amikacin, colistin and doxycycline to $88.2 \%$ each [32]. According to Alami et al., E. coli had a sensitivity rate of $99 \%$ for fosfomycin, colistin, amikacin, cefoxitin and imipenem [33]. The same author reports resistance rates of $76 \%$ for amoxicillin, 54\% for amoxicillin + clavulanic acid, $46 \%$ for 1 st generation cephalosporins (C1G), 34\% for Ciprofloxacin, 19\% for 3rd generation cephalosporins (C3G) and $14 \%$ for aminoglycosides. E. coli resistance to antibiotics has become an alarming problem in Morocco. This situation is the consequence of the selection pressure due to the massive prescription and the often abusive use of broad spectrum antibiotics, both in hospital and in community settings [33].

According to De Mouy et al., the resistance rates of $E$. coli in community urinary tract infections were as follows: ampicillin (60.5\%), amoxicillin + clavulanic acid (65.9\%), gentamicin (98.8\%), nalidixic acid (93.4\%), norfloxacin (97\%), ciprofloxacin (97\%), fosfomycin (99.3\%), and cotrimoxazole (77.4\%) [34].

Comparing these rates with those of our work, we notice that our $E$. coli strains are more resistant to betalactam and also present a decreased sensitivity to gentamicin, nalidixic acid, ciprofloxacin and cotrimoxazole. Esparcia et al. in a European study reported $E$. coli strains with zero susceptibility to imipenem and $33.5 \%$ to sulfamethoxazole + Trimethoprim [35]. Here, we note that our E. coli species are more sensitive to colistin.

In France, in the elderly in 2013, the authors reported a sensitivity of $E$. coli to fosfomycin at $95 \%$ [36].

Klebsiella pneumoniae strains were sensitive to cefoxitin (75\%), imipenem (66.66\%), ceftazidime (75\%), amikacin (75\%), gentamicin (66.66\%), chloramphenicol (75\%) and colistin (100).

For Maxwel et al. Klebsiella pneumoniae strains were sensitive to cefoxitin (76.92\%), ertapenem (75\%), imipenem (75\%), ceftriaxone $(64.29 \%)$ ceftazidime (64.29\%), amikacin (93.33\%), tobramycin (73.33\%), gentamicin (66.67\%), fosfomycin (93.33\%), colistin and chloramphenicol (100\%) [10].

Alami et al. reported for Klebsiella pneumoniae, a very high sensitivity rate for C3G and aminoglycosides (99\%) and for piperacillin and amoxicillin + clavulanic acid (50\%) [34]. Traoré et al. reported a sensitivity of Klebsiella pneumoniae to colistin (94.1\%); cefoxitin (81.3\%); amikacin (78.6\%) [37]. On the other hand, our study found that the strains are resistant to amoxicillin (100\%); amoxicillin + clavulanic acid (66.66\%) and ciprofloxacin (33.33\%).

In the study by Maxwel et al. Klebsiella pneumoniae strains were resistant to amoxicillin + clavulanic acid and piperacillin (80\%), cefalotin (53.33\%), nalidixic acid (66.67\%), sulfamethoxazole + trimethoprim and norfloxacin (60\%).

In the elderly in France in 2014, Thibaut et al. recorded a sensitivity of Klebsiella pneumoniae strains to fosfomycin at $75 \%$, cotrimoxazole at $35 \%$, ciprofloxacin at $26 \%$ and nalidixic acid at $19 \%$ [36].

For Pseudomonas aeruginosa, the results of our study show that the strains of 
Pseudomonas aeruginosa were sensitive to ceftazidime, amikacin and colistin at $100 \%$.

For Moumile et al. the strains of P. aeruginosa were sensitive to ceftazidime and resistant to ciprofloxacin [23]. According to Maxwel et al., Pseudomonas aeruginosa strains were sensitive to beta-lactams (imipenem, aztreonam, ceftazidime, cefepime and ticarcillin + clavulanic acid at $100 \%$ and to ticarcillin, piperacillin and piperacillin + tazobactam at $75 \%$ ), aminoglycosides (gentamicin, tobramycin and amikacin at $75 \%$, netilmicin at $33.33 \%$ ), and ciprofloxacin (100\%) [10]. According to Filali et al., the most active $\beta$-lactams on Pseudomonas Aeruginosa are ceftazidime and imipenem. Amikacin was more active than gentamycin and almost $39 \%$ of the strains were resistant to ciprofloxacin [38].

\section{Study Limitations}

- The diagnosis of the urinary tract infection could not be made within 48 hours to allow us to distinguish between community and nosocomial infection.

- The distinction between simple and complicated urinary tract infection (parenchymal involvement) was not specified.

- Our sample size was relatively small and CBSU was not systematically performed.

- The inclusion criteria are based on the signs of call, thus underestimating the asymptomatic forms.

\section{Conclusion}

UTI is common in the elderly, its clinical presentation is polymorphic, and enterobacteria are the most incriminated group of bacteria.

\section{Acknowledgements}

We thank all the staff of the hospital of Kayes, the CHU Point G and the Mali-GAVARDO hospital of Sébenicoro.

\section{Conflicts of Interest}

The authors declare no conflicts of interest regarding the publication of this paper.

\section{References}

[1] Bendhaouhmaidi, B., Boussema, F. and Ketari, S. (2011) Les infections urinaires chez les personnes âgées. La Revue francophone de gériatrie et de gérontologie, 18, 230-232.

[2] Hmaidi, B.B.D., Boussema, F., Aydi, Z., Baili, L., Ketari, S., Rhouma, S.B., et al. (2011) Les infections urinaires (IU) du sujet âgé. La Tunisie Medicale, 89, 920-923.

[3] Gavazzi, G., Delerce, E., Cambau, E., François, P., Corroyer, B., de Wazières, B., et al. (2013) Diagnostic Criteria for Urinary Tract Infection in Hospitalized Elderly Patients over 75 Years of Age: A Multicenter Cross-Sectional Study. Médecine et 
Maladies Infectieuses, 43, 189-194. https://doi.org/10.1016/j.medmal.2013.02.006

[4] Boscia, J.A., Kobasa, W.D., Knight, R.A., et al. (1986) Epidemiology of Bacteriuria in an Elderly Ambulatory Population. The American Journal of Medicine, 80, 208-214. https://doi.org/10.1016/0002-9343(86)90011-2

[5] Nicolle, L.E. (2009) Urinary Tract Infections in the Elderly. Clinics in Geriatric Medicine, 25, 423-436. https://doi.org/10.1016/j.cger.2009.04.005

[6] Foxman, B. (2002) Epidemiology of Urinary Tract Infection: Incidence, Morbidity and Economic Cost. The American Journal of Medicine, 113, 5-13. https://doi.org/10.1016/S0002-9343(02)01054-9

[7] Phillips, C.D., Adepoju, O., Stone, N., et al. (2012) Asymptomatic Bacteriuria, Antibiotic Use, and Suspected Urinary Tract Infections in Four Nursing Homes. BMC Geriatrics, 12, Article No. 73. https://doi.org/10.1186/1471-2318-12-73

[8] Schmiemann, G., Kniehl, E., Gebhardt, K., et al. (2010) The Diagnosis of Urinary Tractinfection: A Systematic Review. Deutsches Ärzteblatt International, 107, 361-367. https://doi.org/10.3238/arztebl.2010.0361

[9] Wagenlehner, F.M., Weidner, W., Pilatz, A. and Naber, K.G. (2014) Urinary Tract Infections and Bacterial Prostatitis in Men. Current Opinion in Infectious Diseases, 27, 97-101. https://doi.org/10.1097/QCO.0000000000000024

[10] Sampson, M.M. (2015) Infection urinaire chez le sujet âgé à l'Hôpital Militaire d'Instruction Mohamed V de Rabat. Thèses de pharmacie, Maroc, 03.

[11] McGeer, A., Campbell, B., Emori, T.G., Hierholzer, W.J., Jackson, M.M., Nicolle, L.E., et al. (1991) Definitions of Infection for Surveillance in Long-Term Care Facilities. American Journal of Infection Control, 19, 1-7. https://doi.org/10.1016/0196-6553(91)90154-5

[12] Delamare, V. and Garnier, M. (2006) Définition de la personne âgée. In: Dictionnaire des termes de médecine, 29th Edition, Maloine, Paris.

[13] Caron, F. (2014) Société de Pathologie Infectieuse de Langue Française. Mise au point. Diagnostic et antibiothérapie des infections urinaires bactériennes communautaires de l'adulte. http://www.infectiologie.com/site/medias/Recos/2014-infections_urinaires-court.pdf

[14] Agence Française de Sécurité Sanitaire des Produits de Santé (2008) Recommandations de bonne pratique: Diagnostic et antibiothérapie des infections urinaires bactériennes communautaires chez l'adulte.

http://www.infectiologie.com/site/medias/_documents/consensus/afssaps-inf-urinai res-adulte-argumentaire.pdf

[15] Collège des Universitaires des Maladies Infectieuses et Tropicales (CMIT) (2012) Anti-infectieux: Antibiotiques. ePilly TROP: Maladies infectieuses et tropicales. 22th Edition, Vivactis Plus Ed, 44-57.

http://www.infectiologie.com/site/medias/enseignement/ePillyTROP/ePillyTROP.p df

[16] Traoré, H. (2006) Les infections urinaires dans le service de néphrologie et d'hémodialyse de l'hôpital du point G. These Med, Bamako, 206.

[17] Raschilas, F. (2006) Epidémiologie des maladies infectieuses du sujet âgé. Soins Gérontologie, 61, 4-6.

[18] Cédric, C. and Régis, G. (2012) Infection urinaire du sujet âgé. Rev Geriatr A, 37, 119-128.

[19] Delamonica, M.C. and Chatelier, F.J. (1997) Particularités de l'infection urinaire du sujet âgé. Rev Geriatr, 2, 597-600. 
[20] Tristan, C., Catherine, C. and Nathalie, F. (2004) Prise en charge d'une infection urinaire chez le sujet âgé. Soins Gérontologie A, 47, 39-42.

[21] De Wazières, B. and Rainfray, M. (2009) Infections urinaires du sujet âgé. In: Belmin, J., Ed., Gériatrie pour le praticien, 2nd Edition, Masson, Paris, 367-369.

[22] Rapport d'activité 2008. ONERBA, Décembre 2010, p.112 http://www.onerba.org/IMG/pdf/onerba_rapport2008_LD.pdf

[23] Moumile, K., Carbonne, A., Rouquet, M.-L., Gamard, M.-N., et al. (2004) Étude descriptive des bactériémies dans un hôpital gériatrique universitaire. Pathologie Biologie, 52, 557-565. https://doi.org/10.1016/j.patbio.2004.07.040

[24] Christophe, T., Fabienne, L.-T. and Catherine, M. (2006) Écologie bactérienne des prélèvements urinaires: Intérêt dans le choix de l'antibiothérapie probabiliste des infections urinaires du sujet âgé hospitalisé. La Rev Gér A, 31, 77-82.

[25] Delerge, E. (2014) Etude des bactériuries du sujet âgé hospitalisé: Critères cliniques déterminant les diagnostics d'infection. Thes Med, Université de Grenoble, Grenoble, 312. http://dumas.ccsd.cnrs.fr/dumas-00628102

[26] Akpabie, A. and Prieur, B. (2001) Germes urinaires et leur sensibilité aux antibiotiques en gériatrie. Médecine et Maladies Infectieuses, 31, 461-467. https://doi.org/10.1016/S0399-077X(01)00247-5

[27] Bathily Diarra, M. (2002) Sensibilité aux antibiotiques des bactéries à gram négatif isolées d'infections urinaires à l'Hôpital National du Point G. These Pharm, Bamako, 46 .

[28] Epok, J.C. (1998) Aspects épidémiologiques et étiologiques des infections urinaires à l'hôpital national du Point G. These Pharm, Bamako, 5.

[29] Hsueh, P.R., Hoban, D.J., Carmeli, Y., Chen, S.Y., Desikan, S., Alejandria, M., et al. (2011) Consensus Review of the Epidemiology and Appropriate Antimicrobial Therapy of Complicated Urinary Tract Infections in Asia-Pacific Region. The Journal of Infection, 63, 114-123. https://doi.org/10.1016/j.jinf.2011.05.015

[30] Siby, F.B. (1992) Etude clinique, bactériologique et thérapeutique des infections urinaires dans les services de Médecine interne de l'hôpital national du Point G. These Med, Bamako, 18.

[31] Faucher, N. and Billebaud, T. (2000) Les infections urinaires du sujet âgé. Rev Gér, 25, 507-513.

[32] Traoré, A.M., Minta, D.K., Cissé, H., Coulbaly, I., Niaré, B., Diallo, I., et al. (2012) Current Epidemiological and Bacteriological Profile of Urinary Tract Infections in the Infectious Diseases Department of the Point G University Hospital, Bamako. Mali. Rev. CAMES-Series A, 13, 122-126.

[33] Alami, M., Filali, A., Lahlou, H. and Mahmoud, M. (2011) Resistance Profile of Escherichia coli Strains Isolated from Urine at Hassan II University Hospital in Fez. Microbiology Laboratory. 4th Scientific Day, CHU Hassan II, Fez.

[34] De Mouy, D., Fabre, R., Cavallo, J.-D., et al. (2007) Community-Acquired Urinary Tract Infections in 15 to 65 Years Old Female Patients in France. Susceptibility of $E$. coli According to History: AFORCOPI-BIO Network 2003. Médecine et Maladies Infectieuses, 37, 594-598. https://doi.org/10.1016/j.medmal.2006.11.007

[35] Esparcia, A., Artero, A., Eiros, J.M., Balaguer, M., Madrazo, M., et al. (2014) Influence of Adequate Antimicrobial Therapy on Prognosis in Elderly Patients with Severe Urinary Tract Infections. European Journal of Internal Medicine, 25, 523-527. https://doi.org/10.1016/j.ejim.2014.04.009

[36] Thibaut, S., Caillon, J., Marquet, A., Grandjean, G., Potel, G., Ballereau, F. and Microbi- 
ology Laboratories of the MedQual Network (2014) Epidemiology of Third-Generation Cephalosporin-Resistant Community Acquired Enterobacteria Isolated from Elderly Patients. Médecine et Maladies Infectieuses, 44, 57-62. https://doi.org/10.1016/j.medmal.2013.11.008

[37] Traoré, A.M., Minta, D.K., Cissé, H., Kaya-Soukho, A., Coulbaly, I., Diallo, K. Fomba, M., et al. (2012) Nosocomial Urinary Tract Infections, Place of Klebsiella pneumoniae in the Infectious Diseases Department of the CHU du Point G. Bamako. Rev. CAMES-Series A, 13, 118-121.

[38] Filali Baba, A., Alami, M., Lahlou, H., Yahyaoui, Gh. and Mahmoud, M. (2011) Epidemiology and Resistance Profile of Urinary Tract Infections with Pseudomonas aeruginosa. Microbiology Laboratory, 4th Scientific Day, CHU Hassan II, Fez. 